\title{
LAS PALABRAS NO ENTIENDEN LO QUE PASA...
}

Elsa Leone Doctora en Medicina con postgrado en Psiquiatría Infantil de la UDELAR

Miembro de la AUDEPP

A Maro Plá de Arévalo, cuyas palabras me faltaron al escribir esta ponencia.

A Marcelo Viñar, Daniel Gil y tantos otros compañeros de Uruguay, Argentina y Chile, quienes me prestaron las suyas para poder hacerla. 


\section{Acerca del texto}

El texto «Las palabras no entienden lo que pasa...» fue publicado originalmente en 1995, en el primer número de la serie Interrogantes, titulado $L a$ violencia. Este libro, cuya realización estuvo a cargo de la AUDEPP y la editorial Fin de Siglo, recogía las ponencias de varios autores presentadas durante las jornadas AUDEPP se interroga sobre la violencia, que tuvieron lugar el 31 de julio de 1993 en el Club Banco República.

La ponencia de Elsa Leone, cuyo título cita el primer verso del poema de Salvador Puig (de 1968) por la muerte del Che Guevara, formó parte del panel Ley-saber-transgresión en aquellas jornadas.

En la década del ochenta, antes y después del fin de la dictadura, la autora y un grupo de compañeras y compañeros de la AUDEPP integraron la Comisión por el Reencuentro de los Uruguayos (CRU), que prestaba atención a los familiares de los presos, a quienes volvían del exilio y a los que iban saliendo del penal. La CRU participó también en la organización de la venida de Europa de los niños «hijos del exilio», en el mes de diciembre de 1983. Los textos consultados para el trabajo que se expuso en las jornadas de 1993 y cuya relectura aquí se propone fueron en parte la transmisión de una experiencia y sus aportes teóricos, un complemento a esa práctica de la que sus autores participaron. 
El miedo seca la boca, moja las manos y mutila. El miedo de saber nos condena a la ignorancia, el miedo de hacer nos reduce a la impotencia. La dictadura militar, miedo de escuchar, miedo de decir, nos convirtió en sordomudos. Ahora la democracia, que tiene miedo de recordar, nos enferma de amnesia; pero no se necesita ser Sigmund Freud para saber que no hay alfombra que pueda ocultar la basura de la memoria.

Eduardo Galeano, «La desmemoria» (1991, s. p.).

El propósito de este texto es pensar e interrogarnos sobre el tema de la violencia. ¿Pero de qué violencia hablaremos?: ¿de la individual?, ¿de la familiar?, ¿de la social?... ¿Podemos trazar fronteras entre unas y otras o hay inevitablemente una codeterminación entre ellas? ¿Cuál es la causa de la violencia? ¿Cómo y desde dónde pensarla?...

Tratemos de plantearnos algo concreto: la violencia en el Uruguay de hoy. Pero ¿podemos pensarla en un Uruguay aislado de la problemática de Latinoamérica y de la incertidumbre que se vive a nivel mundial, un mundo donde se han perdido puntos de referencia y donde se proclama el fin de la historia y la muerte de las ideologías, en este fin de siglo tan convulsionado?

Realmente creo que no. Y porque sigo convencida «de lo inevitable del cambio, no solo como ley natural e histórica, sino como imperativo ético» (Arias, 1953), y porque en la historia de la humanidad siempre ha habido y habrá ese horizonte utópico que las nuevas ideologías pretenden arrebatarnos, por todo eso es que me centraré en un punto que pienso que tiene que ver con el tema de esta mesa: ley-saber-transgresión. Esto es, preguntarnos sobre la violencia y su relación con la ley de impunidad. 
La ley de impunidad, hipócritamente llamada Ley de Caducidad de la Pretensión Punitiva del Estado, con su mandato implícito de renunciar al derecho y al deber de saber lo que pasó durante la dictadura, ¿no fomentaría la trasgresión a la Ley y, por lo tanto, la violencia?

Antes que nada, quiero dejar claro que sé que la violencia no tiene una causa única. Tampoco pretendo hacer un enfoque totalizador. De ahí la necesidad de encuentros transdisciplinarios como este.

Por otra parte, todo discurso no solamente está atravesado por lo que pasa en el entorno cultural, sino que, como dice Michel Foucault, está determinado por el discurso cultural. Por lo tanto, de una manera u otra, las circunstancias históricas, políticas y sociales siempre van a estar presentes e incidiendo. Esto es, para que quede claro, que no es del psicoanálisis exclusivamente desde donde hablaremos, sino desde las varias dimensiones que nos atraviesan en lo social, lo cual incluye también lo que nos pueda aportar la teoría psicoanalítica. Y debo aclarar, además, que este es un enfoque personal, que no compromete a la institución AUDEPP.

\section{LEYYTRANSGRESIÓN}

Nos preguntábamos si la ley de impunidad no fomentaría la transgresión a la Ley. Con dicha ley quedaron impunes los que violaron, torturaron y asesinaron, o sea, los que durante la dictadura militar transgredieron la Ley, violando cotidianamente las normas jurídicas que invocaban para legitimarse. Implica, entonces, confirmarlos en su convicción de que la acción violenta en el marco del Estado es impune, que nunca se sabrá lo que pasó ni quiénes fueron los responsables y, por lo tanto, que la Justicia no podrá tocarlos. En ese sentido, la justicia será burlada para siempre.

La Ley es algo que deviene en custodia de la sociedad, para lo cual es sancionada, aunque no desconocemos que el dicho popular es bien sabio 
y que «hecha la ley, hecha la trampa». Pero con la ley de impunidad, ¿no se legitimaría, de alguna manera, que se puede delinquir sin que queden pruebas o, mejor dicho, que dichas pruebas se pueden silenciar?

Si bien esta ley estaría referida solamente a los que violaron los derechos humanos durante la dictadura, nos preguntamos:

¿La impunidad no se introdujo en el sistema político y en la vida cotidiana? ¿No produciría efectos de los cuales podría surgir algo así como: «puedo hacer cosas horrendas por las cuales nadie me va a pedir cuentas ni las tendré que rendir»? ¿No sería esto una incitación a transgredir la Ley y ello no contribuiría a la violencia? ¿Esta justificación del terror, así como tantas otras violencias que se ejecutan en nombre del Estado para «salvaguardar» la paz y la democracia, no formarán parte ya del imaginario social y, por lo tanto, estarán en todos nosotros sin que nos demos cuenta?

Sin querer hacer una extrapolación desde el psiquismo individual a lo social, que sería reduccionista, trataremos de pensar las condiciones subjetivas y que trascienden al sujeto que pudieron favorecer la aprobación de la ley. Sin dejar de tener en cuenta, como fundamentales, las razones políticas y económicas que están en la base de su procesamiento —que viola no solamente las promesas preelectorales sobre expectativas de verdad y justicia y los acuerdos internacionales que firmó nuestro país, sino también, y lo que es más importante, a la propia Constitución-, nos preguntamos si no hubo como un deslizamiento desde la impunidad de la dictadura a la impunidad en la democracia, salvaguardada por esta ley.

En la dictadura los militares asumieron un poder que era despótico y arbitrario. No defendían la ley aplicándola; ellos «eran la Ley». Decidían, sin ninguna lógica que pudiera ser anticipada, qué era lo prohibido y qué lo permitido, qué era lo penable y qué lo no penable, y había, en general, una desproporción entre la transgresión y la punición. Recordemos lo 
que nos podía pasar si en un acto patrio se entonaba con más fuerza el «iTiranos, temblad!».

Para imponer los horrores que cometieron, pretendieron apropiarse de la verdad absoluta de la ley, disfrazada bajo un estatuto jurídico, en una suerte de impostura de ley, que legalizó el terror.

Marcelo Viñar nos decía en 1993:

Como psicoanalistas podemos intentar interpretar el dispositivo pseudolegal de las dictaduras en América Latina y sus efectos en la esfera subjetiva transindividual. Nuestro postulado es que hay una sagacidad perversa en la lógica del orden instituido que utiliza los efectos psicológicos y sociales de la impostura. Es precisamente en razón de esa eficacia de la impostura que las dictaduras latinoamericanas actuales se escudan bajo una pseudo-legalidad costosa, obsesiva y espectacular que se agrega como un ornamento a los métodos clásicos y conocidos de la represión. Fachada jurídica que no sería necesaria si no se buscara otra eficacia más allá de la que puede lograr la violencia brutal y desnuda. (s.p.)

Esa otra eficiencia, pensamos, sería el apropiarse de instancias internas del psiquismo humano, de control y vigilancia, como forma de permanencia. De esta manera, es por el camino del miedo internalizado que esta impostura de ley viene a impregnar toda la trama social. Por lo tanto, los afectados no serían solamente las víctimas que pasaron por la experiencia del horror de la tortura, sino la sociedad toda.

Freud nos dice que la interiorización de la ley es una necesidad intrínseca del funcionamiento del aparato psíquico. El niño pequeño, en su indefensión, tiene una necesidad absoluta de los padres o de figuras sustitutas para sobrevivir. Por temor a la pérdida de su amor, que lo dejaría en el desvalimiento y lo llevaría a la muerte, siente que debe obedecerles y que no debe enfrentarlos. Esto hace que los vivencie como figuras 
todopoderosas, protectoras, por un lado, y, por el otro, terribles y despóticas, todo lo cual quedará inscripto en el psiquismo.

Más adelante, con el Edipo, la identificación con los padres no solo hace que tengamos de ellos tales gestos, características o manera de ser, sino también lo que ellos nos transmiten, proponen y exigen dentro de la pauta cultural en la que están inmersos. Esta tarea luego es continuada por los maestros, los profesores y las diferentes figuras de autoridad del entorno social. En el interior del psiquismo se constituye, pues, un ideal, que no es solo un modelo de identificación, sino también una exigencia de realización que se impone al yo del sujeto como instancia vigilante, que juzga y castiga, a la que llamamos superyó. Y es en el superyó donde quedaría internalizado el padre todopoderoso y terrible que mencionábamos anteriormente.

Freud nos muestra cómo a través de la sublimación se produciría ese pasaje de los padres a otras figuras de autoridad, e incluso a Dios, o a formas más sublimadas, como sería la sujeción a dos fuerzas soberanas y abstractas: la razón y la necesidad. Daniel Gil (1990) nos dice:

El sujeto, cuanto más defectuoso haya sido su proceso de sublimación, cuanto menos abstractas sean las figuras superyoicas, cuanto más alejadas estén de la soberana Razón y Necesidad, más dependiente, más sometido, menos libre se encontrará, constituyéndose dentro del propio sujeto una relación donde el yo estará en una posición masoquista (de servidumbre voluntaria) y el superyó en una posición más despiadada y sádica de instancia tiránica (M. Viñar), y el sujeto más alejado de su libertad, es decir, de asumir su deseo y de ser sujeto deseante. (s.p.)

Queremos agregar que, en la estructura del psiquismo humano, así como está la relación de dependencia con los padres que llevaría al sometimiento, también están el enfrentamiento y la rebeldía con el padre 
en el Edipo y luego con otras figuras de autoridad, que llevarían a la búsqueda de la independencia y a la libertad.

Nos preguntamos si esa impostura de ley no intentó aprovecharse de estas características del psiquismo humano de sometimiento a una instancia tiránica, que está en todos nosotros, más o menos fuertemente arraigada, y que es una consecuencia de la internalización de la figura más arcaica del padre de la primera infancia, todopoderoso y, por lo tanto, vivido como terrible y despótico: el padre de la horda para Freud o el padre del segundo tiempo del Edipo para Lacan.

¿No encajaba bien esta figura del padre terrible con las figuras terribles y despóticas del poder militar? ¿No se habrá querido aprovechar de eso para que se entronizara el poder despótico en la dictadura y esto se deslizara luego en la aprobación de la ley de impunidad? Los discursos y la propaganda a favor de la ratificación de la ley, en lo que se nos decía que si no había impunidad se podía volver a un régimen dictatorial, ¿no apuntaban a reafirmar el miedo y la sujeción psíquica a la mencionada instancia tiránica?

Hoy, a seis años y medio de aprobada la ley, ¿no siguen en la fantasmática y en la realidad todas estas cosas? Y esto: ¿no sería generador de paralización, por un lado, y de violencia, por otro?

\section{SABER}

Preguntarnos por el presente y el futuro requiere inevitablemente del conocimiento del pasado.

La impunidad se sustenta en el silencio y el olvido. «Tenemos que mirar hacia el futuro. No debemos tener los ojos en la nuca», se nos dijo insistentemente. Pero ¿se puede construir un proyecto de futuro, apropiarnos 
de la historia, tener identidad, con el mandato de «no se puede ni se debe saber lo que pasó», como queda implícito en la ley de impunidad?

Este no saber, esto que queda silenciado, esto que se pretende que se olvide - y que no es el olvidar que surge del recordar y elaborar, como nos muestra el psicoanálisis-, esto que no se recupera simbólicamente: ¿no retornará como síntoma en la violencia individual y social?

Saber lo que pasó permitiría elaborar (aunque: ¿se podrá elaborar realmente tanto horror?) el sufrimiento vivido y trasmitirles a los jóvenes esta vivencia, para que ellos se reapropien de la historia y puedan asegurar así la continuidad de la memoria y la reestructuración de la trama social.

El conocimiento de la verdad y el que se hiciera justicia hubieran sido el acto simbólico de rescate de la memoria histórica, imprescindible para la vida de los pueblos y la cultura.

No hubo triunfo político, pero hubo triunfo simbólico. Hoy prácticamente nadie en el Uruguay niega que hubo tortura, muerte y desapariciones. «No pudimos hacer que se cumplieran la verdad y la justicia, pero eso no hace que haya que declinar la verdad y la memoria» (Gil, 1993, s.p.). Los casi dos años en que se luchó por el referéndum fueron un ejercicio de memoria que ofició como altoparlante de la defensa de los derechos humanos.

«El silencio lastima a quienes vivieron el terror, pero sobre todo a las generaciones jóvenes que ven dificultada su identidad, ya que no pueden construirla con una historia silenciada» (s.d.). Esto nos lleva a pensar en los jóvenes y lo que pasó con ellos en relación a dicha problemática. Sería muy importante plantearnos un nuevo encuentro, que los incluya a ellos, para pensar juntos esta temática. Por ahora, simplemente dejaremos planteadas algunas interrogantes...

¿Pueden los jóvenes tener proyectos de futuro, como los teníamos nosotros, con tantos años de historia silenciada? Este agujero en la memoria histórica ¿no dificultaría el logro de la identidad? Para constituir la 
identidad son fundamentales las figuras identificatorias. ¿Cuáles fueron estas durante la dictadura?

\begin{abstract}
El dilema era, para los jóvenes, que su proceso identificatorio debía desarrollarse en el interjuego entre las identificaciones previas con sus padres o sustitutos, las posibles identificaciones con personas o grupos que resistían como respuesta social a la dictadura o, lo más peligroso, la imposición como ideal de la figura de un Padre Terrible, cuyo discurso era algo así como: «no podés elegir, sino lo que yo te impongo», que podría conducirlos a la identificación con el agresor o a una sumisión devastadora. (s.d.)
\end{abstract}

Hemos perdido nuestros mitos y estamos en la dificultosa búsqueda de otros. Entonces, lo que no les pudimos trasmitir a las nuevas generaciones, sumado a la incertidumbre que se vive a nivel mundial, ¿no les dificulta encontrar un camino, su camino?

¿Son los jóvenes quienes, «tan indiferentes como a veces rápidamente los tildamos o con una nueva mentalidad y con lo que tienen a mano, están tratando de crear sus propios mitos o utopías»? (s.d.).

Para terminar, diremos que, tal como ya dijo Hanna Segal (s.f.), «Nosotros psicoanalistas, que creemos en el poder de la palabra, en los efectos terapéuticos de verbalizar la verdad, no debemos permanecer callados» (s.p.).

\title{
ADENDA 2020
}

Después de 25 años de escrito, con la nueva lectura para su publicación, me doy cuenta de que no estoy totalmente de acuerdo con el título que había elegido.

Las palabras no entendían lo que pasaba ante el horror. Pero había otras palabras que sí entendían lo que pasaba, aunque estaban prohibidas. 
Igual siempre alguna se escapaba y encontraba la forma de resistir, como veíamos, por ejemplo, en expresiones del canto popular y en tantas otras cosas.

Luego de la dictadura, las palabras fueron recuperando el poder decir lo que pasaba. Pero al no saber la verdad de lo que sucedió, ¿qué hacemos con lo que se nos sigue ocultando?

Elsa Leone

$\S$

\section{REFERENCIAS BIBLIOGRÁFICAS}

ArIAS, H. (dir.). (1953). Revista Cathedra, 10 [revista de cultura eclesiástica]. Bogotá.

FreUd, S. (1979a). Inhibición, síntoma y angustia. En Obras completas (vol. xx, pp.71-164). Buenos Aires: Amorrortu.

FReUd, S. (1979b). Duelo y melancolía. En Obras completas (vol. xIv, pp.235258). Buenos Aires: Amorrortu.

Galeano, E. (1991). El libro de los abrazos. Montevideo: Ediciones del Chanchito.

GIL, D. (1990). Entre la servidumbre y la libertad. En El terror y la tortura. Montevideo: EPPAL.

GIL, D. (1993). Prólogo. En M. Ulriksen y M. Viñar (comps.), Fracturas de memoria. Crónicas para una memoria por venir. Montevideo: Trilce.

VIÑAR, M. (1993). La ley como impostura. En M. Ulriksen y M. Viñar (comps.), Fracturas de memoria. Crónicas para una memoria por venir. Montevideo: Trilce. 
